\title{
Plurality in Ethnobiology: A Look Towards 2017
}

\author{
OPENӘACCESS \\ DOI 10.14237/ebl.7.2.2016.861
}

Copyright (C) 2016 by the author(s); licensee Society of Ethnobiology. This is an open-access article distributed under the terms of the Creative Commons Attribution-NonCommercial 4.0 International Public License (https://creativecommons.org/licenses/by-nc/4.0), which permits non-commercial use, distribution, and reproduction in any medium, provided the original author and source are credited.

Diversity, especially biological and sociocultural, is central to many ethnobiologists' academic perspectives and core values. It serves as a first principle for the study of human and non-human life in the broadest sense and helps provide meaning to many kinds of people interested in the wellbeing of humans and environments. These kinds of diversity are increasingly well-represented in Ethnobiology Letters and the Society of Ethnobiology's other publications, Journal of Ethnobiology and Contributions in Ethnobiology. In their pages, ethnobiologists have documented biological diversity in past and present anthropogenic landscapes, explored the close connections between biodiversity and cultural diversity, celebrated the limitless diversity of ethnic identities and worldviews, and argued for the importance of actively promoting biodiversity through ethical conservation.

As the end of 2016 draws near and we reflect on its surreal events in the United States and throughout the world, we are tempted to mourn the bleak future of diversity. We question how it will be affected by the seemingly fast pace and unforeseen directions of recent social and political change. As temperatures spike to unprecedented winter levels in the polar region, we read of the possibility that the next presidential administration of the United States may pull back from the promising Paris Climate Agreement. We see examples of increasing religious intolerance and populist extremism in Europe and North America during the worst global migrant crisis since World War II. There is continued violence toward Indigenous peoples and their lands as economic and political pursuits trump local cultural and ecological values. Academic publishing and the production of knowledge are in upheaval as the commercialization of science and commodification of scientific production escalate.

Against this backdrop, we close this issue of Ethnobiology Letters with our reaffirmation of the importance of all forms of diversity in this journal, our academic field, and the environmental and human contexts we study. We applaud ethnobiologists and scholars in related fields for their dedication to disciplinary and epistemological plurality in education and research institutions and publishing venues. We praise the high value currently placed on inclusive science through collaborative research and publishing. We acclaim the increasing availability of academic space for Indigenous and minority voices. We are inspired by globalizing scientific discourse and its potential to bridge geographical, cultural, and political boundaries. We are proud to remain among the few journals offering true open access publication without asking authors or readers to pay fees. We take this opportunity to communicate our continued editorial dedication to these principles in 2017.

December 30, 2016

James R. Welch

Escola Nacional de Saúde Pública, Fundação Oswaldo Cruz, Rio de Janeiro, RJ, Brazil. welch@ensp.fiocruz.br

John M. Marston

Department of Archaeology, Boston University, Boston, MA, USA.

marston@bu.edu

Elizabeth A. Olson

History, Sociology, and Anthropology Department, Southern Utah University, Cedar City, UT, USA.

elizabetholson@suu.edu 